\title{
Bristled Micromachines
}

\section{Nagy Lajos*}

University of Miskolc, Faculty of Mechanical Engineering and Informatics, 3515, Miskolc-Egyetemváros, Hungary

\begin{abstract}
The paper deals with specific problems in area of the in-pipe machine design. Main purpose of the machine is to locomote inside pipe for pipe wall inspection otherwise for cable drawing into the pipe. The main attention is concentrated to the bristle, which has the key influence to the machine locomotion.
\end{abstract}

Keywords: In-pipe machine, bristle, mechatronics, pipe.

\section{Introduction}

Paper deals with in-pipe machines which are able to locomote inside pipe with aim to realize inspection of inner pipe wall or cable drawing inside pipes. There are many pipe systems which require periodical inspection of inner pipe wall as prevention of disaster (steam generator of nuclear power plant, heat exchanger, gas pipeline, etc.

The in-pipe machine is explored from the viewpoint of locomotion effectiveness. State of the inner pipe wall has the most significant impact to locomotion efficiency (traction force and steady traction velocity of machine). Consequently, deviation of inner pipe diameter and shape deviation of inner pipe surface are dominant disturbance quantities from the viewpoint of locomotion controlling [1].

Wheeled in-pipe machines tend to slipping when dirty wall occurs, so unconventional carrying elements are preferred mainly for using inside pipe with small diameter (less then $25 \mathrm{~mm}$ ).

Bristles are one of the possible carrying elements for in-pipe locomotion. The contact forces are generated between tips of pre-loaded elastic bristles and inner pipe wall. Elasticity of bristles eliminates the influence of these geometric deviations of inner pipe surface which can cause the locomotion troubles.

Producers of the pipe have no mention about production tolerances of inner pipe surface and these deviations also can changes because of settling of sediments on inner pipe wall.

Bristled in-pipe machines (fig. 1) use the inertial stepping principle, anisotropic friction difference principle, inchworm principle etc. All these principles use the elastic bristles or similar parts for obtaining of contact force between the machine body and inner pipe wall for generating of locomotion.

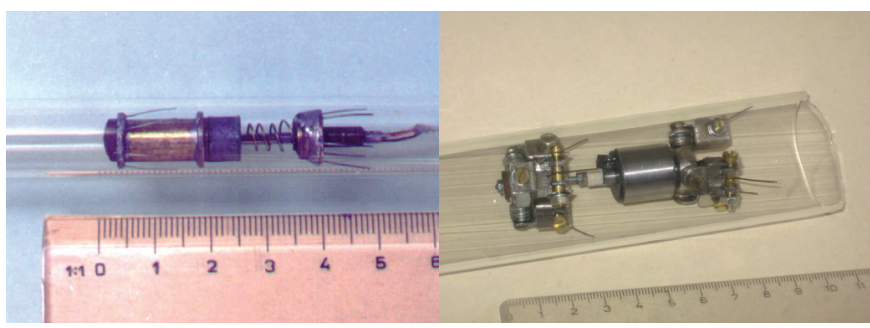

Fig. 1: Bristled in-pipe micromachines. 
Bristles play the key role for locomotion of machine inside pipe. From the viewpoint of functional principle, bristles can be arranged as passive elastic beam otherwise as controlled active bristles. Active controlling of bristles is complicated and expensive. First step is to examine passive bristles and main task is to find optimum geometry and arrangement of them.

\section{Passive Bristle as Elastic Beam}

Bristles are attached diagonally at angle of machine body. Bristle is as elastic beam with large deflection (approximately 25\% of its length). Bristles are arranged around the machine body and span of free ends of these bristles are bigger than inner pipe diameter (fig. 2).

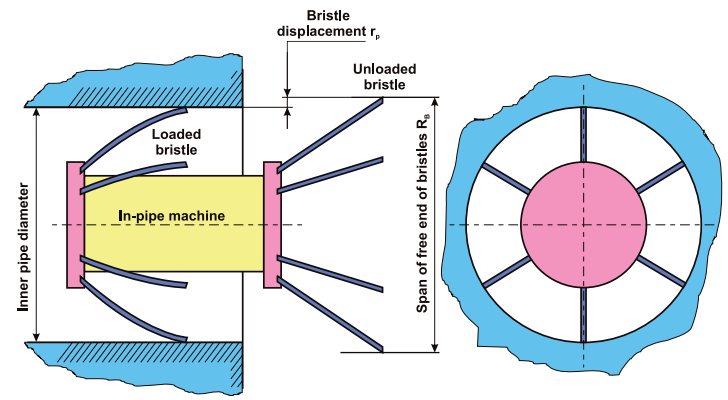

Fig. 2: Bristle loading caused with rigid pipe wall [1].

It means that deformation of bristles are forced and defined with inner pipe diameter. Consequently, deflections of bristles are as result of pipe wall rigidity. Analysis of the force situation leads to obtain of normal force between bristle tip and inner pipe wall. Friction force occurs between the bristle tip and pipe wall. Experience and previous analysis show that if the bristle is attached at angle, then friction force has anisotropic character. Bristle deflection is very large in comparing with bristle length. It means that it is not possible to use conventional simplified Bernoulli differential equation for bristle deflection description. It is necessary to use exact form of Bernoulli differential equation or different kind of description [1-6].

\section{Bristle Deflection Description Via using of Exact form of Bernoulli Differential Equation of Deflection Curve}

Deformation of beams is described via using of simplified Bernoulli equation (1): $\frac{d^{2} y}{d x^{2}}=-\frac{M(x)}{E J_{z}}$

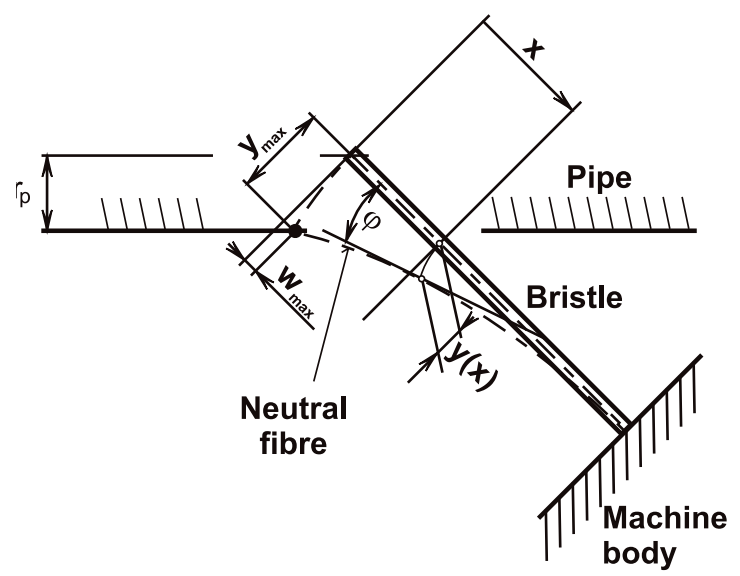

Fig. 3: In-pipe micromachine bristle [7].

This equation is valid only in case of deformation of conventional beams with low deflection, consequently deflection curve only lightly differs from straight line. Declination angle of this line is very low and it is defined as:

$\varphi=\operatorname{arctg}\left(\frac{d y}{d x}\right)$

Equation 1 - simplified Bernoulli equation comes from exact Bernoulli equation (3). In case of large deformation the equation 1 is not valid and it is necessary to use exact form - equation 3.

$\frac{\frac{d^{2} y}{d x^{2}}}{\left[1+\left(\frac{d y}{d x}\right)^{2}\right]^{3 / 2}}=-\frac{M}{E J_{z}}$

Many references listed the value of validation of equation $1[6,7,8,9]$. Small deflection is assumed in case when deflection is less than $2 \%$ of length of beam and maximum deflection of declination angle of deflection line is less than $1^{\circ}$. If one of these conditions is overcome, then the deflection is big and the exact form of Bernoulli equation has to be used for description of beam.

Deflection of bristles reaches the values up to $40 \%$ of the bristle length. It means that bristle 
deflection is big and we have to use the exact form - equation 3. This equation is differential equation of second order. Analytical solution of this equation leads to elliptical integrals and solving of them is complicated also for simple forms of function of momentum $\mathrm{M}(\mathrm{x})[6,7]$.

\section{Description of Bristle Via using of Pseudo Rigid Body Model}

Concept of pseudo rigid body model has been developed for simplification of analysis of compliant mechanisms [3]. Compliant mechanisms are modeled as rigid bodies coupled with springs. Normally, flexible parts show the large deflection and solving of them needs methods of solving of nonlinear systems.

Pseudo rigid body theory enables to make model composed from rigid bodies and consequently it is possible to use conventional Newton's methods of force analysis. Main advantage is that using of this method brings the information about force situation for overall mechanism.

Bristle can be described as fixed beam and pseudo-rigid body model of this beam consist of two rigid beams connected through the "characteristic joint" and non-linear spring. The characteristic joint presents displacement of centre of arc radius which is as trajectory of end point of deformed bristle (fig. 3). Non-linear spring presents the stiffness or resistance to deformation of bristle against the applied force. Position of characteristic joint is defined with "factor of characteristic radius" - $\gamma$. Position of free end of bristle $(x, y)$ is described with parameters $\mathrm{a}$ and $\mathrm{b}$ ( $\mathrm{b}$ - presents deflection of bristle) [3]:

$$
\begin{aligned}
\frac{a}{L_{S}} & =1-\gamma(1-\cos \Theta) \\
\frac{b}{L_{S}} & =\gamma \cdot \sin \Theta
\end{aligned}
$$

where: $L s$ - length of bristle, $\gamma$ - factor characteristic radius, $\Theta$ - angle of pseudo-rigid body.

$$
\text { Valid limitation of equations (4) and (5) is }
$$
expressed with angle of pseudo-rigid body [3, 4]:

$$
\begin{aligned}
& \Theta<\Theta_{M A X}=0,85 \cdot \operatorname{arctg}\left(-\frac{1}{n}\right) \\
& -0,5<n<10,0
\end{aligned}
$$

where: $\Theta_{M A X}$ - maximum allowed angle of pseudorigid body, $n$ - ratio of values of horizontal and vertical force applied on free end of bristle.

Ratio $n$ can be expressed with angle of equivalent load $\Phi$ :

$\Phi=\operatorname{arctg}\left(-\frac{1}{n}\right)$

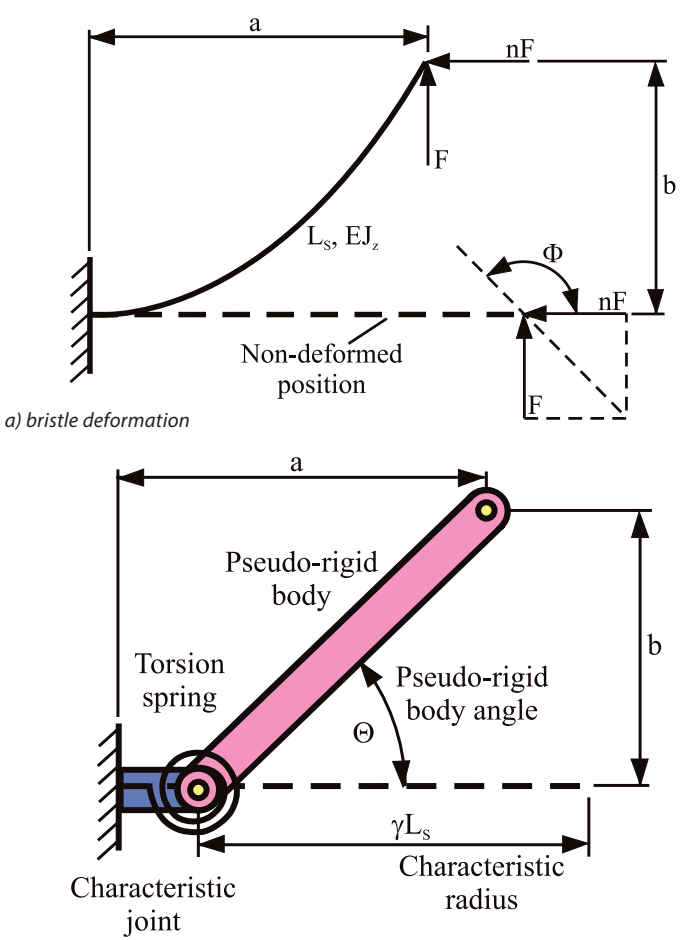

b) pseudo-rigid model of bristle

Fig. 4: Bristle - beam and its pseudo-rigid body model [4, 10].

Factor of characteristic radius $\gamma$ can be derived from equations (4) a (5):

$a_{2} \cdot \gamma^{2}+a_{1} \cdot \gamma+a_{0}=0$

where coefficients of equation are:

$a_{2}=L_{S}^{2}, \quad a_{1}=-a \cdot L_{S}, \quad a_{0}=-\frac{\left(a-L_{S}\right)^{2}+b^{2}}{2}$

References [4, 10] have mention about the factor of characteristic radius and it is presented in graphical form (fig. 5). Factor of characteristic radius is equal $\gamma=0,85$ for simple transverse load $n=0$. 




Fig. 5: Dependence of the characteristic radius factor $\gamma$ on parametern $[3,10]$.

Factor of characteristic radius can be expressed also with next equations:

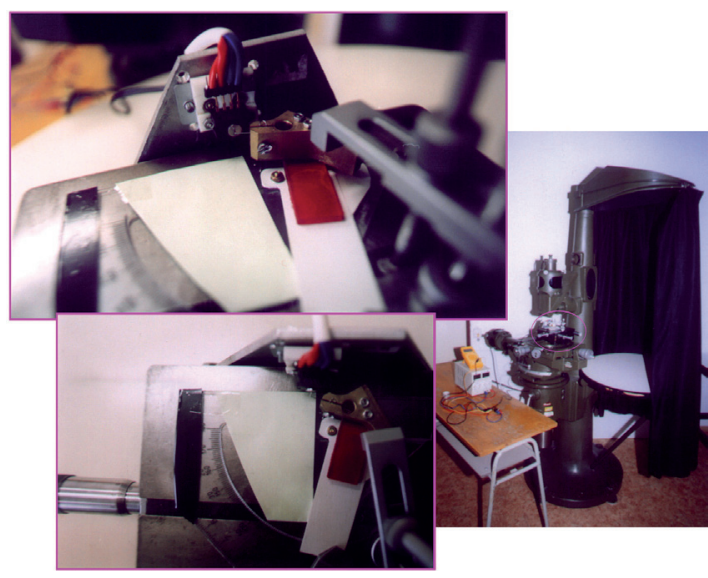

Fig. 6: Geometrical mapping of the bristle deflection trajectory [1].

$\gamma=-0.0182867 \cdot n+0.852144$ for $0<n \leq 0.5$

with regression coefficients 0,94 and 0,99 for equation 9 and 10 .

\section{Experimental Identification of Factor of Characteristic Radius $\gamma$}

Factor of characteristic radius $\gamma$ is obtained via using of experimental geometry mapping of deflection trajectory for static mode of bristle loading. Another way is using of finite element method model.

Experimental apparatus (fig. 6) have been developed. Geometry trajectory of free end of bristle has been measured (with profilprojector) also with load force of bristle (with force sensor).

Obtained trajectory (fig. 7) of end point of bristle are fitted with arc and centre point of the arc is searched characteristic joint and radius of this arc is characteristic radius i.e. conjunction of bristle length $L s$ and factor of characteristic radius $\gamma$.

Measurement shows the possibility to identify of factor of characteristic radius value $\gamma=0,88 \pm 0,05$ (Expanded uncertainty is obtained in accordance with EAL-R2 standard with coverage factor 2, with probability 0,95). Measurements also show that this value is independent from cross-section area and material property of bristle.

Finite element method has been used with special solvers for large displacement work. Characteristic radius factor obtained via using of finite element method is $\gamma=0,87$.

Theoretic value of characteristic radius factor obtained through the solving of Bernoulli exact differential equation has value $\gamma=0,85$. Deviations between values are only small. Pseudo-rigid bodies' methodology is useful for analytical solving of various compliant mechanisms. Also finite element method can be used for quick orientation in solved problem. Source of deviations can be various as uncertainty of measurement, representation of beam constraint in finite element model etc.

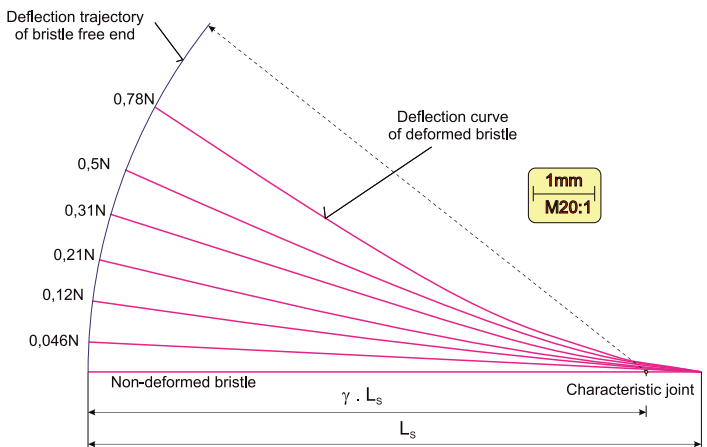

Fig. 7: Bristle deflection mapping [1].

\section{Identification of Bristle Stiffness}

A Stiffness of bristle is necessary to know because of characteristic joint spring in pseudo-rigid model theory. This identified stiffness will be used for 
completed of pseudo-rigid body model of bristle. Identification process gives also answer to question: Where is the usage limit of bristle? It means how is the maximum allowable limit of bristle deflection, which causes only elastic deformation. Plastic deformation of bristle can causes the malfunction of in-pipe machine. Allowable deflection is value for defining of working interval for elimination of geometric deviation of inner pipe wall during the in-pipe machine locomotion.

Designed experimental apparatus (fig. 6) can be used also for identification of bristle stiffness and elastic deformation limit. Principle of measurement is based on cyclic loading/unloading of bristle and measurement of deflection and load force. Every step of cycling has bigger value of deflection. Experiment stops when plastic deformation occurs. Figure 8 shows the measured values. As it is visible the plastic deformation occurs at deflection with value $4,51 \mathrm{~mm}$. Linear area has been fitted with linear approximation which gives information about stiffness.

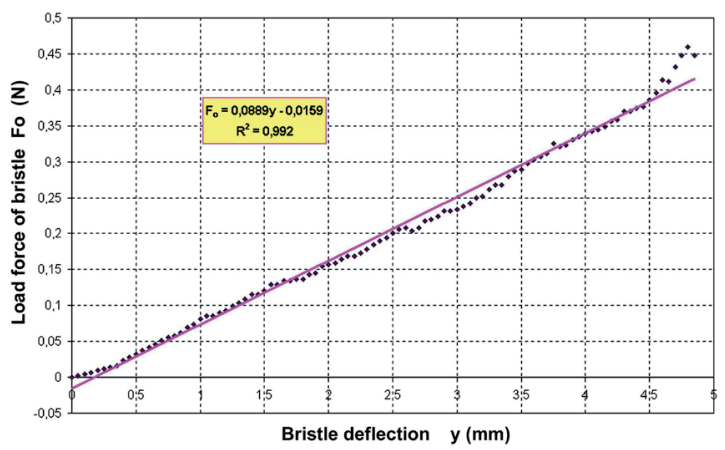

Fig. 8: Dependence of transverse force on bristle deflection [1]

\section{Conclusions}

Paper shows the modeling of bristle used as contact part in in-pipe machine. Bristle has large deflection which causes the solving problems. Pseudo-rigid body model has been also used as suitable method of modeling of bristle. This model will be used for optimizing of bristle geometry for obtaining of maximum elimination of inner pipe geometric deviation during the machine locomotion. This geometry has key impact to steady state locomotion velocity of machine and traction force of machine [11-22].

\section{Acknowledgments}

The authors would like to thank to Slovak Grant Agency - project KEGA 048TUKE-4/2014 and VEGA 1/1205/12. Paper is the result of the Project implementation: University Science Park TECHNICOM for Innovation Applications Supported by Knowledge Technology, ITMS: 26220220182, supported by the Research \& Development Operational Programme funded by the ERDF.

\section{References}

[1] Matašovská, T.: Contribution to design of in-pipe machine inside pipe with geometric deviation. PhD thesis. Technical University of Kosice: 2005.

[2] Burns, R. H., Crossley, F. R. H.: Kinetostatic synthesis of flexible link mechanism. ASME No. 68-Mech-36, 1968.

[3] Kuryło, P.: The study of residual stresses in the surface layer. In: Acta Mechanica Slovaca. Roč. 17, č. 4 (2013), s. 6-15. ISSN 1335-2393.

[4] Papacz, W., Kuryło, P. Tertel, E.: A sample of calculation of anisotropy loaded beams. In: American Journal of Mechanical Engineering. Vol. 1, no. 7 (2013), p. 300-303. ISSN 2328-4110.

[5] Howell, L., L., Midha, A.: Parametric deflection approximations for end-loaded, large-deflection beams in compliant mechanisms. Transactions of the ASME, Vol. 117, March 1995. s. 156-165.

[6] Howell, L. L., Rao, S. S., Midha, A.: Realiability - based optimal design of bistable compliant mechanism. Journal of Mechanical Design. Vol. 116, december 1994. s. 1115-1121.

[7] Virgala, I., Kelemen, M., Varga, M., Kuryło, P.: Analyzing, Modeling and Simulation of Humanoid Robot Hand Motion. In: Procedia Engineering : Modelling of Mechanical and Mechatronic Systems MMaMS 2014 : 25th-27th November 2014, High Tatras, Slovakia. Vol. 96 (2014), p. 489-499. - ISSN 1877-7058.

[8] EAL-R2 Expression of the uncertainty of measurement in calibration.

[9] Ondráček, E., Moráček, M., a kol.: Strength and Elasticity I., Praha: SNTL, 1979

[10] Trebuňa, F., Šimčák, F.: Robustness of part of mechanical systems. Edition of scientifically publications. Technical University of Kosice, Faculty of Mechanical Engineering. Emilena publishing. Kosice: 2004

[11] Trebuňa, F., Buršák, M.: Limit states. Breaks. Grafotlač Prešov 2002, ISBN 80-7165-362-4

[12] Trebuňa, F., Jurica,V.: Handbook of elasticity and strength, VŠT Košice, Alfa Bratislava 1977

[13] Howell, L., L.: Compliant Mechanisms, Wiley-Interscience; 1 edition, 2001, ISBN 978-0471384786, 480 pages

[14] Božek, P. - Korshunov, A. I.: Mechatronic system control proposal using mathematical expression of reliability verification method. In: Vestnik lževskogo gosudarstvennogo 
Acta Mechanica Slovaca

Journal published by Faculty of Mechanical Engineering - Technical University of Košice

techničeskogo universiteta. - ISSN 1813-7903. - Vol. 60, No. 4 (2013), s. 34-40.

[15] Božek, P., Goga, V. Korshunov, A. I.: Robot Arm control based on INS with the support of simulation in MATLAB/Simulink. In: Vestnik Iževskogo gosudarstvennogo techničeskogo universiteta. - ISSN 1813-7903. - Vol. 60, No. 4 (2013), s. 2025

[16] Trebuňa, F., Šimčák, F., Huňady, R.: Operational vibration analysis of railway transport complex. Acta Mechanica Slovaca. Roč. 16, č. 3 (2012), s. 26-32. - ISSN 1335-2393.

[17] Božek, P., Pivarčiová, E.: Flexible manufacturing system with automatic control of product quality. In: Strojarstvo. - ISSN 0562-1887. - Vol. 55, No. 3 (2013), p. 211-221].

[18] Kelemenová, T., Duchoň, F. Puškár, M., Kelemen, M., Kuryło, P., Prada, E., Lipták, T.: Influence of pipe geometric deviations on in-pipe machine locomotion. In: Applied Mechanics and Materials. Vol. 611 (2014), p. 221-226. - ISSN 1660-9336.

[19] Trebuňa, F. et al.: Methodology for experimental verification of safety of packages for transport of spent nuclear fuel. Acta Mechanica Slovaca. Roč. 16, č. 3 (2012), s. 34-41. - ISSN 1335-2393.

[20] Božek, Pavol: Robot path optimization for spot welding applications in automotive industry. - registrovaný: Master Journal List, Web of Science. In: Tehnički Vjesnik - Technical Gazette. - ISSN 1330-3651. - Vol. 20, No. 5 (2013), s. 913-917.

[21] Papacz, W., Tertel, E., Frankovský, P., Kuryło, P.: Analysis of the fatigue life of composite leaf springs. In: Applied Mechanics and Materials. Vol. 611 (2014), p. 346-351. - ISSN 1660-9336.

[22] Prajová, V., Božek, P.: Management for detection of defective objects in automated robot production line. In: IN-TECH 2013 : Proceedings of International Conference on Innovative Technologies, Budapest, Hungary 10.-13.09.2013. - Rijeka : Faculty of Engineering University of Rijeka, 2013. - ISBN 978-953-6326-88-4. - S. 465-471 